\title{
Inferences from beading of a retinal vein draining a choroidal melanoma
}

\author{
ROBERT N JOHNSON, ALEXANDER R IRVINE, AND DEVRON H CHAR \\ From the Department of Ophthalmology, and the Ocular Oncology Unit, University of California, San \\ Francisco, California, USA
}

SUMMARY Beading of a retinal vein draining a choroidal melanoma is reported, showing that the endothelial proliferation producing the beading is a response to some blood borne factor(s) traversing the vein and that retinal capillary non-perfusion adjacent to the beaded vein is not a necessary part of the process.

Venous beading is a well recognised sign of proliferative retinopathy in diabetes. ' It is usually associated with capillary non-perfusion of the adjacent retina. Endothelial cellular proliferation has been demonstrated histologically in the beaded veins. ${ }^{2}$ It is uncertain if this proliferation is a response to ischaemia of the adjacent retina or to a factor in the blood passing through the vein from some more peripheral area of ischaemic retina. ${ }^{25}$

This paper describes a patient with a prominent beading of a retinal vein draining a choroidal melanoma. The unusual aspect of this case is the absence of any retinal capillary non-perfusion. This indicates that the factor(s) responsible for the beading in this case were carried to the venous endothelium by the blood traversing that vein from the melanoma. Ischaemia of the adjacent retina was not necessary.

\section{Case report}

A 57 -year-old male was noted to have a $10 \times 12 \times 7$ $\mathrm{mm}$ moderately pigmented choroidal melanoma in the inferonasal quadrant of his right eye. Vision was $20 / 25$ and the anterior segment was normal. The tumour had a collar button configuration. The inferonasal retinal vein coursed over the tumour and abruptly entered the collar button. This retinal vein showed prominent beading (Fig. 1). Fluorescein angiography showed that this vein filled from the

Correspondence to A R Irvine, MD, Department of Ophthalmology, Room U-490, University of California, San Francisco, California 94143 , USA. tumour as well as from the surrounding retinal capillaries. It filled at essentially the same time as the other retinal veins, and there was no apparent retinal capillary non-perfusion. It is of note that the angiogram also showed early irregular leakage from an area that appeared most consistent with a small frond of neovascularisation on the distal portion of the collar button (Figs. 2, 3B). This appears to be a second indicator of the angiogenic potency of this tumour.

\section{Discussion}

Our patient showed marked venous beading. The unusual aspect of this case is that the affected vein

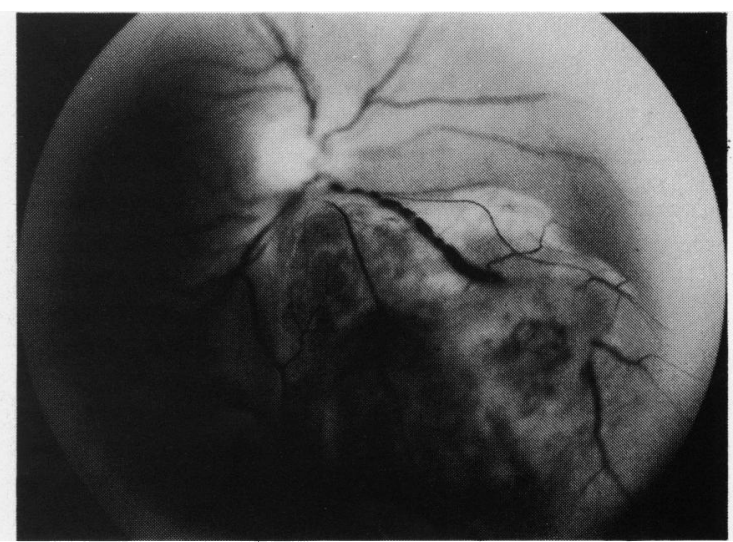

Fig. 1 Pigmented melanoma showing collar button configuration. The retinal vein overlying the tumour appears to enter the tumour and shows prominent beading. 


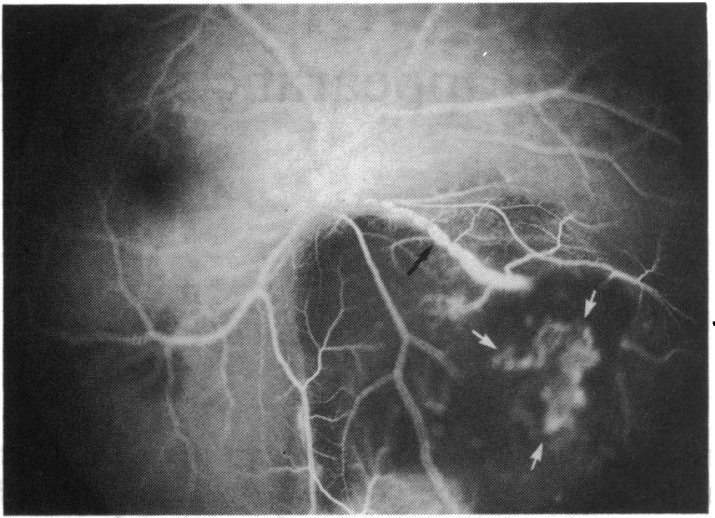

Fig. 2 Arteriovenous phase angiogram showing normal filling of the beaded retinal vein (black arrow). The surrounding retina shows good capillary perfusion. Some early fluorescein leakage from the area of probable neovascularisation over the collar button is present (white arrows).

traversed normally perfused retina. This suggests that venous beading is not contingent on surrounding retinal hypoxia. Rather, it appears that some vasoproliferative factor(s) produced by the melanoma influenced tissues downstream and produced the beading in the draining retinal vein. Further evidence of some presumed vasoproliferative factor(s) emanating from the tumour was seen in the tuft of apparent neovascularisation on the surface of the tumour.

This work was supported in part by an unrestricted grant from That Man May See, Inc., to the UCSF Ocular Oncology Unit.

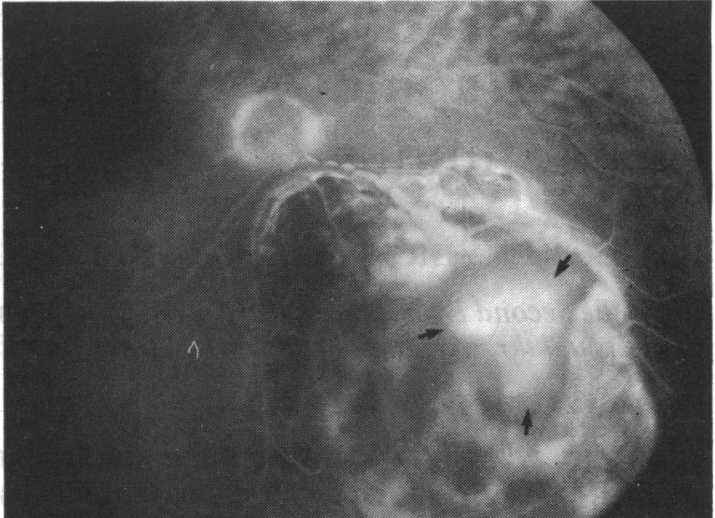

Fig. 3 Late phase angiogram demonstrating dye leakage from the apparent area of neovascularisation over the collar button (arrows).

\section{References}

1 Murphy RP, and Patz A. The natural history and management of nonproliferative diabetic retinopathy. In: Little H, Patz A, eds. Diabetic retinopathy. New York: Thierne-Stratton, 1983: 225-41.

2 Bresnick GH, Engerman R, Davis MD, deVenicia G, Myers FL. Patterns of ischemia in diabetic retinopathy. Ophthalmology (Rochester) 1976; 81: 694-709.

3 Folkman J, Merler E, Abernathy C, Williams G. Isolation of a tumor factor responsible for angiogenesis. J Exp Med 1971; 33: 275-88.

4 Cavallo T, Sade R, Folkman J, Cotran R. Tumor angiogenesis: rapid induction of endothelial mitoses demonstrated by autoradiography. J Cell Biol 1972; 54: 408-20.

5 Finkelstein D, Brem S, Patz A, Folkman J, Miller S, Ho-Chen C. Experimental retinal neovascularization induced by intravitreal tumors. Am J Ophthalmol 1977; 83: 660-4.

Accepted for publication 16 January 1986. 